\title{
A EDUCAÇÃO CONTEMPORÂNEA ATRAVÉS DAS IMAGENS: JUVENTUDE, CIBERCULTURA E FORMAÇÃO DOCENTE
}

\author{
Patrícia Marcondes de Barros ${ }^{1}$
}

\begin{abstract}
Resumo
O objetivo deste artigo é analisar quais são os desafios educacionais na formação de professores frente às novas gerações moduladas pela tecnologia, relacionadas à pós-modernidade. Trata-se de uma análise reflexiva acerca da imagem e suas reverberações no âmbito educacional na contemporaneidade. Os jovens "pós-modernos" ou "nativos digitais" formam o que se denominou juventude "Y" (geração do milênio ou geração digital) e " $Z$ ", oriundos da sociedade imagética e de grande desenvolvimento tecnológico. Uma das questões que se impõem à educação para as gerações atuais é a do entendimento dessa cultura permeada de imagens que, como agentes simbólicos, nos fornecem subsídios para o entendimento dos novos valores contemporâneos, propiciando a partir disso a ressignificação das práticas pedagógicas, indo além das fronteiras da educação formal.
\end{abstract}

Palavras-chaves: Juventude, cibercultura, educação contemporânea, imagens.

\section{Abstract}

This article aims at analysing the educational challenges in the training of teachers regarding the new generations mediated by technology and postmodernity. It is a reflective analysis about the image and its reverberations in the educational field nowadays. "Postmodern" young people or "digital natives" form what is called "Y" youth (millennial or digital generation) and " $Z$ " generation, derived from the image society and of great technological development. One of the main questions for present generation in education is the understanding that permeated culture of images, as symbolic agents, provide subsidies for the understanding of new contemporary values, leading to recreation of teaching practices, beyond the boundaries of formal education.

Keywords: Youth, cyberculture, contemporary education, images.

\section{Introdução}

O presente artigo se constitui numa interface do projeto de Pós-Doutorado da autora e tem como objetivo analisar as reverberações da cultura imagética no âmbito educacional, especificamente, entre os jovens contemporâneos denominados genericamente de "Y" e " $Z$ ". As imagens como agentes simbólicos nos fornecem subsídios para o entendimento dos novos valores contemporâneos, propiciando a partir de então a ressignificação das práticas pedagógicas, indo além das fronteiras da educação formal.

Em um primeiro momento, trataremos acerca das novas gerações, personificadas através da figura do estudante, do aluno, que traduz as premissas relacionadas à pós-modernidade. Estas são imbuídas dos novos desafios, especificamente, para a formação docente. No segundo momento, discutiremos a necessidade de se compreender e se apropriar adequadamente da cultura imagética, no âmbito educacional. Tal apropriação e ressignificação servem como ferramenta de exploração dos mecanismos sociais de valores, atitudes, de formação de gosto e conteúdos como condição de investimento na formação de sujeitos sociais históricos relacionados com a sociedade contemporânea (CARVALHO, 2013).

\footnotetext{
${ }^{1}$ Doutora em História e Sociedade (Unesp, 2007).
} 


\section{Os nativos digitais, a pós-modernidade e os novos desafios para a formação docente}

Para tratarmos acerca do tema proposto, faz-se necessário esclarecer quem são esses nativos digitais, personificados na figura dos alunos contemporâneos, que se denominou genericamente como juventude "Y" e "Z" e os novos desafios na formação docente frente às construções de novas subjetividades.

Os nativos digitais são oriundos do ambiente de grande desenvolvimento tecnológico que trouxeram mudanças paradigmáticas no modo de pensar, produzir, consumir (CASTELLS, 1999) e consequentemente, de "ensinar e aprender" relacionadas à pós-modernidade. A geração Y, comumente chamada de geração do milênio ou geração digital (jovens que já nasceram sob a égide da tecnologização propiciada pela internet) e a nascida posteriormente, denominada de “Z” (que vem de 'zapear', quando o jovem costumeiramente muda de um canal para outro na televisão) se utilizam com propriedade dos meios tecnológicos, e assim como trocam os canais da televisão, "zapeando", fazem desta prática o mote de sua visão de mundo mutável, instantâneo.

Tal como o funcionamento dos computadores e a navegação no espaço virtual com os hiperlinks, as gerações contemporâneas se conectam a tudo na sua comunicação em rede, contínua, realizando multitarefas, todas com ênfase no tempo "presente" na perspectiva de resultados rápidos e aplicabilidade dos conteúdos escolares para a vida profissional. Esta esfera, a profissional, deve render lucros rápidos, a fim de obter todas as benesses que a liberdade de consumo possa oferecer.

Green e Bigun (apud FÁVERO SOBRINHO, 2010) têm se destacado por estabelecer a diferença histórica entre o aluno de "ontem" e o "de hoje". Afirmam que os alunos que estão em nossas escolas são radicalmente diferentes dos alunos de épocas anteriores por apresentarem uma "historicidade pós-moderna", constituída por um conjunto de práticas culturais responsáveis pela produção de sujeitos particulares, específicos, com identidades e subjetividades singulares. Para esse "novo aluno" faz-se necessária a construção de novas narrativas (reconhecendo a diversidade existente no mundo contemporâneo); desde as que se constroem no silêncio e no gesto, até as poéticas e tecnológicas (apud FÁVERO SOBRINHO, 2010).

[...] um sujeito-estudante pós-moderno porque ele apresenta um novo tipo de subjetividade humana - uma subjetividade pós-moderna - que se caracteriza pela efetivação particular da identidade social e da agência social, corporificadas em novas formas de ser e de tornar-se humano (GREEN e BIGUN apud FÁVERO SOBRINHO, 2010, p.2). 
Tendo em vista a desterritorialização propiciada pela internet, os discursos presentes no ambiente educativo devem se coadunar com o da diversidade cultural que permite a "escuta" dos valores do indivíduo e do grupo a que pertence, tendo como base, a perspectiva de circularidade cultural. A ressignificação dos saberes só terá uma apropriação significativa se estiverem relacionados às identidades culturais dos sujeitos individuais e coletivos presentes no âmbito educacional, portanto, faz-se necessário compreendê-las.

Para tratarmos acerca dessas subjetividades moduladas pela perspectiva da pósmodernidade, faz-se necessário elucidar sobre o referido conceito, caracterizado geralmente como antagônico ao de modernidade. Nela, os paradigmas centrais da racionalidade científica e homogeneidade levariam, segundo seus entusiastas positivistas, ao progresso da humanidade, perpassando todas as instâncias sociais e aplainando as diferenças em favor de uma coesão social. Contudo, se instalaria também uma crise, uma contradição histórica que se traduziu em rupturas trazidas quer pelas formas cotidianas do existir, fazendo emergir a necessidade das considerações das heterogeneidades, das diferenças, das desigualdades gritantes, quer pelas fissuras lógicas nas ciências.

A uniformização da modernidade consistiu em um projeto que não suportou o caos, os totalitarismos, os conflitos étnicos, as desigualdades econômicas que geraram a violência e a destruição e propiciaram a crise dos seus paradigmas centrais (GATTI, 2005). No decorrer do século XX, em fins da década de 60, pensadores dos mais diferentes matizes ideológicos proclamaram o fim da modernidade e dos ideais inerentes ao iluminismo-universalismo, caracterizados contextualmente pelas derrotas políticas com as revoluções em curso, com o pósindustrialismo, com a emergência de novas forças políticas e atores sociais, com a vanguarda artística, pelo fim das utopias (tanto as hippies como as socialistas), com o esvaziamento do debate ideológico e com a descrença em relação a alternativas ao processo mundial e a globalização.

Embora a conceituação de pós-modernidade não encontre consenso entre os principais teóricos e suas diferentes manifestações, faz-se notória uma mudança de sensibilidade intensificada a partir da segunda metade do século passado, problematizando as grandes utopias e modelos de análise produzidos nos séculos anteriores, na chamada era moderna. A evidência dos novos fatos socioculturais levou alguns estudiosos a caracterizá-los como "pós-modernos", instalando-se uma polêmica sobre o fim da modernidade.

O desafio pós-moderno não só constitui um corpo diferente de crítica cultural, mas deve também ser visto como "um discurso contextual que tem desafiado os limites disciplinares 
específicos em campos, tais como os estudos literários, a educação, a arquitetura, o feminismo, a arte, a sociologia e muitas outras áreas" (GIROUX, 1995). A sensação de impotência do indivíduo frente a um processo histórico rápido (em consonância com os meios tecnológicos que geram novas subjetividades mutantes) e incompreensível (tendo em vista o mundo fragmentado e descentralizado) tornou-se notória. Surge um novo mundo, com novos argumentos relacionados à tecnociência, às novas tecnologias de informação e da comunicação. Tal revolução científica e tecnológica transformou a cultura, permeou as instâncias sociais e pessoais, e consequentemente, a esfera educacional e suas instituições.

É o universo educacional, desde as séries iniciais até a universidade, o locus de grande visibilidade das mudanças sociais e culturais, tendo em vista a construção das identidades e apreensão da alteridade cultural através dos processos de aprendizagem e socialização. Com a pós-modernidade este universo passa por ressignificações e buscam metodologias que se integrem às novas tecnologias da informação, a interdisciplinariedade, entendida como os saberes comuns a uma ou mais matrizes de conhecimento, e principalmente, a Antropologia, esfera privilegiada que aborda a cultura como dimensão fundadora da sociedade e permite o entendimento da alteridade, importante valor de reconhecimento das diversas culturas que permeiam o ambiente escolar. Da escola à universidade e da informação ao conhecimento, tal enfoque interdisciplinar, aberto aos "novos tempos", enriquece os processos educacionais, as políticas pedagógicas, os currículos, a formação e o exercício do magistério.

O ofício do professor em sala de aula neste devir deve ser constantemente reinventado, o que não se constitui em tarefa fácil, pois além de enfrentarmos condições estruturais precárias dentro de escolas e universidades públicas brasileiras, com carga horária extensa e baixas remunerações para os professores, nos deparamos também com o despreparo (e, consequente desgaste) em lidar com as novas gerações que assinalam expectativas diferenciadas em relação à percepção e apreensão do mundo com novos valores, linguagens e discursos.

Os jovens que já nasceram sob a égide da internet, ou seja, numa realidade tecnológica e virtual muito mais avançada com: celulares, telecomputadores, Ipods, videogames, vídeo e televisores com alta definição em 3D, games jogados em redes sociais, entre outros, construíram sua subjetividade dentro de uma lógica diferenciada de seus pais e professores (NETO, 2010). Denota-se que a instabilidade e a transitoriedade difundidas de forma característica entre os jovens estão inseparavelmente relacionadas a um grande número de condições pós-modernas que têm provocado um mundo com pouca segurança psicológica, econômica e intelectual. $\mathrm{O}$ mundo moderno, das previsibilidades, deu lugar a um planeta no qual o tempo e o espaço são condensados pela virtualidade, onde os jovens, sem pertencerem a algum lugar concreto, vão 
vivendo progressivamente esferas culturais e sociais mutáveis, marcadas por uma pluralidade de linguagens e culturas (GIROUX,1996).

A compreensão da necessidade de um novo processo educacional representa desafio aos estudiosos não apenas da educação, mas também de outras áreas, e instiga o pesquisador a adentrar um movimento investigativo questionador sobre a modernidade e sua possível superação: a constituição do espaço que viria a ser o da pós-modernidade. A cultura imagética neste contexto é fundamental, pois é a principal mediadora das construções das novas subjetividades em questão e compreendê-la e ressignificá-la à luz das práticas docentes contemporâneas tornam-se imprescindíveis.

\section{"A imagem como mensagem": a educação das gerações "Y" e "Z"}

Na sociedade contemporânea, estar na imagem é existir (DEBORD, 2000,p.23).

Pensar uma dimensão educativa no contexto da cultura imagética diz respeito ao conhecimento e ao posicionamento dos sujeitos envolvidos nessa sociedade transmutada em sociedade espetacular, das imagens infográficas, da nova oralidade calcada em uma imagética ubíqua (CARVALHO, 2013).

A cultura contemporânea é permeada por imagens que se fazem presentes como importantes agentes simbólicos, fomentando novas experiências e estratégias educativas que vão além das fronteiras da educação formal. Pretendemos refletir acerca da cultura imagética e sua relação intrínseca com os jovens contemporâneos, para assim postularmos, uma "educação pelas imagens" (indo além do didatismo comumente proposto, de utilização das imagens em sala de aula).

A experiência do jovem contemporâneo não pode ser compreendida fora das suas relações com a imagem e a cultura de consumo que constroem suas subjetividades, identidades. Esta cultura estética/imagética cria novas relações do jovem com o desejo, o conhecimento, enfim, com a vida que o cerca. Pereira (2000, p.2) afirma que "a arte, a educação, as práticas sociais, enfim toda a cultura da época atual começa a ser absorvida pelas representações visuais, favorecendo um estilo fragmentado e experiências fugazes".

Esta fragmentação e imediatismo inerentes aos "novos tempos" junto ao bombardeio visual propiciado pela cultura imagética (aperfeiçoada constantemente pelo desenvolvimento da técnica) desencadearam modificações no próprio sistema sensorial do ser humano (PEREIRA, 2000, p.3). Esta mudança fisiológica nos sentidos ocorre devido ao saturamento pelas imagens e signos, ocasionando um torpor, uma distorção da realidade. Esta tensão entre 
imaginário e real na pós-modernidade leva ao efeito da hiperestimulação, que leva o sujeito à incapacidade de articular signos e imagens em sequências narrativas.

Tal perda do senso de realidade se dá pela vivência crescente da imediatez, da fragmentação e da intensidade das experiências fugazes que constituem o dia-a-dia do homem contemporâneo, principalmente daquele que vive nas grandes metrópoles, o qual dificilmente tem como escapar dos efeitos produzidos, no seu aparelho sensorial, pela comunicação de massas (PEREIRA, 2000, p.3).

Segundo Almeida (1994), a cultura das imagens dentro da perspectiva educacional ressignifica e redimensiona a dimensão estética, circunscreve-se dentro da nova cultura oral, cuja sustentação emana das imagens e dos sons. As imagens nos situam numa certa dimensão fenomênica da cultura e de seus aparatos simbólicos, com os quais nos relacionamos direta ou indiretamente. São as imagens que falam de nosso mundo, da cultura, história e condições existenciais (ALMEIDA, 1994, p.9). "Não se trata 'da reprodução de uma experiência visual, mas da reconstrução de uma estrutura modelo', que tomará a forma de representação mais bem adaptada aos objetivos que estabelecemos para nós [...]”(GOMBRICH apud JOLY, 1996, p. 60). A imagem é linguagem polifônica, contudo, seu sentido se constrói na relação com o outro, que a organiza. Trata-se de uma nova forma de saber.

\section{Considerações finais}

Estamos em um tempo no qual há um crescimento vertiginoso da educação à distância. A velocidade atual do avanço da tecnologia, quando é usada na educação, faz com que o aluno administre rapidamente um grande número de informações, tornando-se criador de mensagens com imagens ou audiovisuais. Mas para que uma nova forma de educação seja instaurada é preciso rever o papel do professor, do aluno e, principalmente, da tradicional forma de ensino na maioria das escolas.

Cabe ao professor romper com a postura de autoridade e prender mais a sua atenção nas questões de percepção, de comunicação e de aprendizagem, como diz Calado (1994). Já ao aluno cabe estar atento à inovação e disposto a refletir sobre uma forma de linguagem que sempre esteve ao seu redor (SILVEIRA, 2001). O processo educativo pode se complementar com materiais/recursos utilizados como imagens e aguçar a motivação desses dois sujeitos envolvidos no processo educativo.

Não há nação desenvolvida que não seja uma nação de leitores. Desde o operário que precisa ler manuais até o advogado que precisa decifrar o "legalês", até o estudante que enfrenta exames, o cidadão que enfrenta as urnas, a dona de casa que lida com a família, o executivo que enfrenta sua papelada, todos os membros de uma sociedade civilizada. A sociedade atual 
exige transformações na área educacional, à medida que a globalização abriu novos caminhos, ampliaram horizontes e precisa cada vez mais de um novo ser humano, crítico, participativo, “antenado" e preparado para as novas descobertas e avanços. Logo, é consequência natural que os próprios professores tenham uma nova postura e acompanhem tais mudanças.

\section{Referências}

ALMEIDA, Milton. José de. Imagens e Sons: a nova cultura oral. São Paulo: Cortez,1994.

CALADO, Isabel. A utilização educativa das imagens. Portugal: Porto, 1994.

CARVALHO, Alexandre Filordi de. Educação e imagens na sociedade do espetáculo: as pedagogias culturais em questão. Educação\& Realidade. vol.38. no.2. Porto Alegre abr.jun. 2013.

CASTELLS, Manuel. A Sociedade em Rede: a era da informação - economia, sociedade e cultura. São Paulo: Paz e Terra, 1999.

DEBORD, Guy. A Sociedade do Espetáculo. Rio de Janeiro: Contraponto, 2000.

SOBrinho, A. F. O ALUNO NÃO É MAIS AQUELE! E AgORA, PROFESSOR? A transfiguração histórica dos sujeitos da educação. ANAIS DO I SEMINÁRIO NACIONAL: CURRÍCULO EM MOVIMENTO - Perspectivas Atuais. Belo Horizonte, novembro de 2010. GATTI, B. A. Pesquisa, Educação e Pós-Modernidade: Confrontos e Dilemas. Cadernos de Pesquisa, v. 35, n. 126, set./dez. 2005. http://www.scielo.br/pdf/cp/v35n126/a04n126.pdf GIROUX, H. Jovens, diferença e educação pós-moderna. In: Castells M, Flecha R, Freire P, Giroux H, Macedo M, Willis P. Novas perspectivas críticas em educação. Porto Alegre (RS): Artes Médicas; 1996. p.63-85.

JOLY, Martine. Introdução à análise da imagem. 4a ed. São Paulo: Papirus, 1996.

NETO, E.S; FRANCO, E.S. Os professores e os desafios pedagógicos diante das novas gerações: considerações sobre o presente e o futuro. Revista de Educação do COGEIME - Ano 19 - n.36 - janeiro/junho 2010.

PEREIRA, Rita Marisa Ribes; SOUZA, Solange Jobim e. O uso da imagem na pesquisa em educação: desafios contemporâneos. In: REUNIÃO ANUAL DA ASSOCIAÇÃO NACIONAL DE PÓS-GRADUAÇÃO E PESQUISA EM EDUCAÇÃO, 2000. Caxambu. Anais.Caxambu: Associação Nacional de Pós-Graduação e Pesquisa em Educação, 2000. SILVEIRA, Edeval. Para uma Pedagogia da Imagem nas Ciências Sociais. In: ECCOS Revista Científica - v. 3, n. 2, p. 83-102. São Paulo: Centro Universitário Nove de Julho, 2001. 